\title{
Distress Identification, Cost Analysis and Pavement Temperature Prediction for the Long-Term Pavement Performance for Western Australia
}

\author{
Ainalem Nega, Hamid Nikraz, Sujeewa Herath, and Behzad Ghadimi
}

\begin{abstract}
Collection and analysis of pavement distress data is a significant component for effective long-term pavement performance. Accurate, consistent, and repeatable pavement distress type's evaluation can reduce a tremendous amount of time and money that has been spending each year on maintenance and rehabilitation of existing pavement distress. The main objective of this study is to identify and quantify of surface distress in a given segment of pavement, to perform details distress rating, to predict pavement temperature and cost analysis of individual pavement distress on heavily urban roads in Western Australia (WA). Field survey were conducted from three regions in WA and two approached were used to evaluate and analysis the pavement distress. First, the probabilistic network Marov-Chain Process method was used to predict the cost analysis for individual asphalt concrete surfaced pavement distress. Second, Statistical Downscaling Model (SDSM) was used to predict pavement temperature for asphalt concrete surface pavement. Meteorological data were collected from Perth, Kalgoorlie, and Albany region in WA, and data were used to develop and validation of the model. Different types of pavement distress level were identified and color photograph illustrated the asphalt concrete surfaced pavement. Results were performed and analysis. Results from this study will be useful resource to Main Roads Western Australia, Western Australia State Highways (WASH), and other pavement related users including to the National Highway System (NHS). In addition, results can be used for pavement management systems (PMSs) purpose.
\end{abstract}

Index Terms-Pavement distress, crack identification, cost analysis, pavement temperature, pavement management, Western Australia.

\section{INTRODUCTION}

In 1987, the Strategic Highway Research Program (SHRP) began the largest and most comprehensive pavement performance in history ever-the Long-Term Pavement Performance (LTPP) program [1]. The Distress Identification Manual for the Long-Term Pavement Performance project was developed to provide a consistent, uniform basis for collecting distress data for the LTPP program. It will allow states and others to provide accurate, uniform, and comparable information on the condition of LTPP test sections. During the program's 20- year life,

Manuscript received April 3, 2014; revised June 20, 2014. This work was supported by Australia Government under Australia Postgraduate Award (APA) grant and Curtin University under Curtin Research Scholarship (CRS) award.

The authors are with the Department of Civil Engineering, Curtin University, GPO Box U1987, Perth, WA 6845, Australia (e-mail: Ainalem.Nega@curtin.edu.au, H.Nikraz@curtin.edu.au, Sujeewa.Herath@curtin.edu.au, Behzad.Ghadimi@curtin.edu.au). highway agencies in United States and other Countries has been collected data on pavement condition, climate, and traffic volumes and loads from more than an thousand pavement test sections [1]. Although developed as a tool for the LTPP program, the manual has broader application. It provides a common language for describing cracks, potholes, rutting, spelling and other pavement distresses being monitored by the LTPP program. Although not specifically designed as a pavement management tool, the Distress Identification Manual can play an important role in a state's pavement management program by ridding reports of inconsistencies and variations caused by a lack of standardized terminology. Most pavement management program do not need to collect data at the level of detail and precision required for the LTTP program, nor are the severity level used in the manual necessary appropriate for all pavement management situations.

Hot-mix asphalt (HMA) is a viscoelastic structural material and its load carrying of the pavement varies with temperature [2], [3]. While accurately determine insitu strength characteristics of flexible pavement are necessary to identify the type of pavement distress and also to predict the temperature. The majority of previously published research either on distress identification or pavement temperature has consisted predicting the annual maximum or minimum pavement temperature to recommend a suitable asphalt performance grade [4]-[7]. However, the predict of pavement temperature has not be related to the pavement distress type, identification and characterization of asphalt concrete surfaced pavement so that cost analysis of individual pavement distress can be included and also analyzed. Thus, to determine long-term pavement performance, pavement distress identification, predict pavement temperature and cost analysis of individual pavement distress are necessary.

The use of full depth asphalt pavements to construct and rehabilitate heavily loaded urban roads has rapidly grown in Western Australia (WA) over the past 5 years. In 2006/7, almost $\$ 429$ million was expended on road network maintenance which made up $38 \%$ of the total road program [8]. The following are some of the works undertaken during the year. Eight regionally based 10-year Term Network Contracts (TNCs) were established to provide road maintenance and rehabilitation services on the State road system and for regulatory signs and road lines on local roads. The contracts provide a range of maintenance services to help ensure that road users are provided with a safe and efficient road system and that the value of the road asset is preserved. During the year \$131 million was spent on direct contract payments [8].

The main objective of this study is to identify and quantify 
of severity of surface distress in a given segment of pavement, to perform details distress rating, to predict pavement temperature and cost analysis of individual pavement distress for Main Roads of Western Australia so that long-term pavement performance can be achieved. This study will be useful resource to the Main Roads Western Australia (MRWA), Western Australia State Highways (WASH) and other pavement related users including to the National Highway Systems (NHS). In addition, it can be used for pavement management systems (PMSs) purposes. Fig. 1 shows the Main Roads Networks in Western Australia.

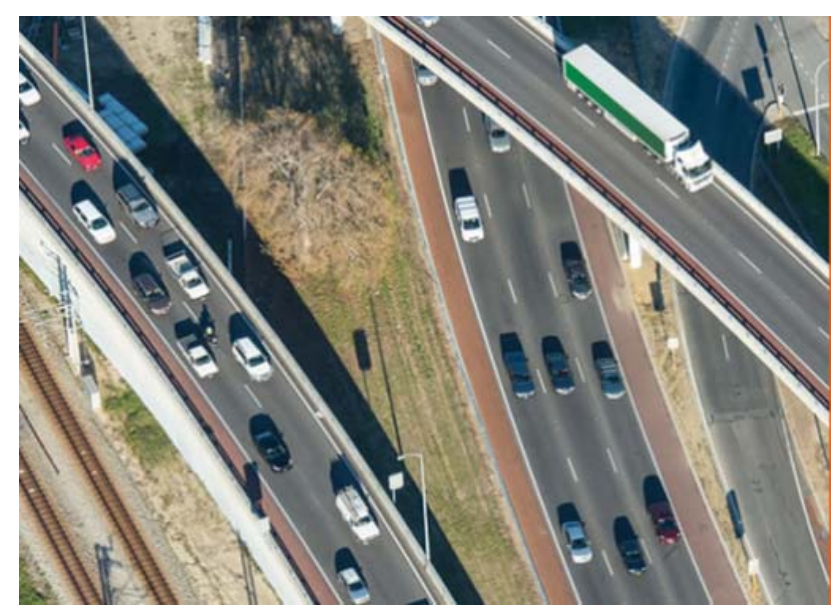

Fig. 1. Main roads networks in Western Australia.

\section{METHODS}

\section{A. Traffic Road Survey}

Field data was conducted to collect data for evaluating the long term pavement performance in Western Australia (WA). This data was collected in Perth, Kalgoorlie and Albany between January and March 2014. Data were collected by the author and staff from Curtin University in Western Australia.

Thirty six roads survey were used to identified and characterized the types of pavement distresses and Distress Identification Manual for Long-Term Pavement Performance by Strategic Highway Research Program [1] was used as a guidance. Depth, width, and length measurements of the pavement distress were taken from each asphalt concrete surfaced pavement roads.

\section{B. Pavement Network Management Tools}

Linear and non-linear programming models are the two main types of algorithms utilized by researchers in developing pavement management optimization models [9]. In linear programming models, key assumptions of all functions that includes objective and constrain function are consider as linear. However, in non-linear programming, this assumption does not accumulate at all [10]. Abaza and Ashur [11] developed their model based non-linear programming. Pavement condition prediction models are significant component of pavement optimization models. These are two types of prediction models: deterministic models and probabilistic models. According to Butt et al. [12], the pavement deterioration rates are often "uncertain", frequently used the probabilistic model based on the Markov process approach to evaluate and analysis the pavement condition [13].

\section{1) Non-linear model algorithm}

The non-linear model for pavement maintenance and rehabilitation optimization is formulated as follows [9], [11]:

Minimize

$$
\sum_{t=1}^{T} \sum_{j^{\prime}=1}^{5} S_{t j} X_{j} L C_{J}
$$

Subject to State transition constrains:

$$
\begin{aligned}
& \left.S_{t j}=\sum_{t=1}^{5} S_{t-1 i}\left\{1-X_{i}\right) D N_{i j}+X_{i} P_{i j}\right\} \\
& \text { for all } t=2, \ldots T ; j=1,2, \ldots 5
\end{aligned}
$$

Non-negativity constraints:

$$
X_{i} \geq 0 \text { for all } i=1, \ldots 5
$$

Sum to one constraints:

$$
\sum_{k=0}^{4} X_{j k}=1 \text { for } i, \ldots 5
$$

Target condition constraints:

$$
S_{T j} \leq e_{T j} \text { for selected }
$$

Budget constrains:

$$
\sum_{j=1}^{5} S_{t j} X_{j} L C_{J} \leq B_{t} \text { for } t=1, \ldots t
$$

where $S_{t j}$ s the proportion of pavement in state $j$ at year $t$; $X_{i} s$ proportion of pavement $i$ receiving treatment; $T$ is number of analysis years; $C_{J} s$ unit cost of applying treatment to pavement in state $j ; D N_{i j} s$ probability that receiving no treatment moves from $i$ to state $j ; P_{i j} s$ probability that pavement receiving new treatment transit from state $i$ to state $j$; $e_{T j} s$ upper limit of proportion of pavement in condition $j$ in final year $T$; and $B_{t} s$ maximum available budget in year $t$. The most common types of pavement cracks in Western Australia are shown in Table I.

TABLE I: Most Common PAVEMENT CRACKING IN WeStern Australia

\begin{tabular}{|l|l|}
\hline Cracking Type & Defined Severity Levels \\
\hline Fatigue cracking $(\mathrm{m} 2)$ & Yes \\
\hline Block cracking $(\mathrm{m} 2)$ & Yes \\
\hline Longitudinal cracking $(\mathrm{m})$ & Yes \\
\hline Reflection cracking at joint (no or $\mathrm{m})$ & Yes \\
\hline Transverse cracking (no or $\mathrm{m})$ & Yes \\
\hline
\end{tabular}

\section{Statistical Downscale Model}

Statistical Downscale Model (SDSM) is multiple regression based tool proposed by Wilby, Dawson and Barrow [14] to describe the linkage between coarse scale 
General Circulation Model (GCM) daily climate predictors and daily maximum or minimum temperature of selected station. SDSM is a combination of the stochastic weather generator approach and a transfer function model with high performance in capturing future inter-annual variability [14]. In downscaling the GCM predictors, SDSM develops inter relationship between predictor (i.e. daily minimum temperature, maximum temperature, rainfall) and predictand (GCM variables). To select the most appropriate GCM predictors, SDSM provides linear correlation analysis by percentage of explained variance (E \%), correlation matrix and scatter plots.

SDSM model is calibrated and validated in monthly basis for three selected regions by considering the daily maximum temperature and minimum temperature as the predictand variables. Initially $26 \mathrm{NCEP}$ variables are subjected for predictor selection and by scatter plot, correlation analysis, explained variance facilities most appropriate predictors are selected

\section{1) Study area and data sets}

Three airports located in Western Australia are subjected to this study. These locations are highly urbanized and road network is highly grown. To obtain the high resolution daily maximum and minimum temperature for these regions SDSM model is employed to downscale GCM predictors. Daily maximum and minimum temperature of each site were obtained from Bureau of Meteorology (BoM), Australia and used as the predictand variable in SDSM model. National Centre for Environmental Prediction (NCEP) reanalyzed data are used as the predictors in SDSM model calibration and validation. In future temperature downscaling Canadian Global Climate Model (CGCM3) data under A2 scenario for the period of (1961-2100) are employed. The details of study area are shown in Table II.

TABLE II: DETAILS OF STUDY AREA

\begin{tabular}{|c|c|c|c|}
\multicolumn{2}{c}{ TABLE II: DETAILS OF STUDY AREA } \\
\hline Region & Latitude & Longitude & $\begin{array}{c}\text { Observed max/min } \\
\text { temp. period }\end{array}$ \\
\hline Perth airport & 31.9522 o S & 115.8589 o E & $1961-1990$ \\
\hline Kalgoorlie & 30.7487 o S & 121.4658 o E & $1961-1990$ \\
\hline Albany & $35.02280 \mathrm{~S}$ & $117.8814 \mathrm{o} \mathrm{E}$ & $1971-2000$ \\
\hline
\end{tabular}

\section{CRACK IDENTIFICATION AND CHARACTERISTICS}

\section{A. Fatigue Cracking}

Fatigue cracking, also known as alligator cracking, is single crack or a series of interconnected cracks caused by fatigue failure of the asphalt concrete [15]. They are the result of repetitive traffic loads (wheel paths), and high deflection often due to wet bases or subgrade but also maybe present anywhere in the lane due to traffic wander. These types of cracking can also lead to potholes and pavement disintegration. A series of interconnected cracks characterizes in early stages of development. It eventually develops into many-sided, sharp-angled pieces, usually less than $0.3 \mathrm{~m}(1 \mathrm{ft})$ on the longest side. Characteristically has chicken wire/alligator pattern in later stages [1]. Longitudinal cracks occurring in the wheel path are rated as fatigue cracking.

An area of cracks with no or only a few connecting cracks, where a crack are not spalled or sealed and with no pumping is evident are considered as low severity fatigue cracking, whereas, if an area of interconnected cracks are forming a complete pattern, where cracks may be slightly spalled or sealed with no pumping is evident are defined as moderate severity fatigue cracking. However, where sections of an area are moderately or severely spalled, multiple interconnected cracks are forming a complete pattern, pieces are missing or move when subjected to traffic or cracks may be sealed and pumping may be evident across the entire pavement roadway are described as high severity fatigue cracking [1], [15]-[17]. This type of failure cannot be treated with crack sealing and/or filling.

\section{B. Block Cracking}

Block cracking is a pattern of cracks that divides the pavement into approximately rectangular pieces. Block cracking is a pattern cracks that divide the pavement into approximately rectangular pieces or blocks. Block cracking, unlike fatigue cracking, will occur throughout of the pavement width, not only in the wheel paths. The blocks range in size from an approximately 0.1 sq.m to 10 sq.m. (1 sq. $\mathrm{ft}$ to 100 sq. $\mathrm{ft}$ ) [1]. These cracks are the result of age hardening of the asphalt coupled with shrinkage during cold weather, and can be effectively treated with crack sealants.

\section{Longitudinal Cracking}

Longitudinal cracks are cracks that are predominantly parallel to pavement's centerline. Location within lane (wheel path versus non-wheel path) is significant. These are caused by thermal stress and/or traffic loading [1]. They occur frequently either at joint between adjacent travel lanes or in between a travel lane and the shoulder, where the hot-mix asphalt density is lower and air voids are higher [16]. Majority cracks are within $25 \mathrm{~mm}$ (1 in) of skip strip or fogs strip/edge of pavement or within $25 \mathrm{~mm}$ (1 in) of the middle of the lane [15]. Cracks may meander into the wheel path, but generally stay out of the wheel path.

Longitudinal cracking sometimes can be associated with raveling, poor adhesion or stripping. Longitudinal cracks which occur in the wheel path and cracks less than mean width $6 \mathrm{~mm}(0.25)$ should be rated as low severity fatigue cracking. The cracks range from mean width of $6 \mathrm{~mm}(0.25 \mathrm{in})$ to $19 \mathrm{~mm}(0.75 \mathrm{in})$ should be also rated as moderate severity longitudinal cracking whereas, if it is greater than mean width $19 \mathrm{~mm}(0.75 \mathrm{in})$ and then, it should be rated as high severity longitudinal cracking [1]. There are two types of longitudinal cracking: wheel path and non-wheel path longitudinal cracking.

\section{Reflection Cracking at Joint}

Reflection cracking is a crack in asphalt concrete overlay surfaces that occur over joints in concrete pavements. These cracks are caused either by cracks or other discontinuities movement with an underling pavement surface that propagate up due to movement at the crack [18]-[20]. An unsealed crack with a mean width of less than $6 \mathrm{~mm}(0.25 \mathrm{in}$.); or a sealed crack with sealant material in good condition and with a width that cannot be determined has low severity, and any crack with a mean width greater than $6 \mathrm{~mm}(0.25 \mathrm{in}$.) and less than $19 \mathrm{~mm}$ (0.75 in.) can be considered as medium severity, and this may also associated with low severity 
random cracking [1], [21]. Any crack with a mean width greater than or equal $19 \mathrm{~mm}$ can develop adjacent moderate to high severity random cracking. They are two types of reflection cracking: transverse and longitudinal reflection cracking.

TABLE III: TYPICAL UNIT COSTS AND EXPECTED LIFE OF TYPICAL PAVEMENT MAINTENANCE TREATMENTS

\begin{tabular}{|c|c|c|c|c|c|}
\hline \multirow[t]{2}{*}{ Treatment } & \multirow[t]{2}{*}{ Code } & \multicolumn{4}{|c|}{ Expected Life of Treatment } \\
\hline & & $\operatorname{Cost} / \mathrm{m}^{2}$ & Min & Average & Max \\
\hline Crack sealing & $\mathrm{CS}$ & $\$ 1.50$ & 2 & 3 & 5 \\
\hline Fog seals & FS & $\$ 1.50$ & 2 & 3 & 4 \\
\hline Slurry seals & SS & $\$ 10.00$ & 3 & 5 & 7 \\
\hline Microsurfacing & MS & $\$ 10.00$ & 3 & 7 & 9 \\
\hline Chip seals & $\mathrm{CS}$ & $\$ 8.76$ & 3 & 5 & 7 \\
\hline Asphalt overlay DGA $30 \mathrm{~mm}$ & AS30 & $\$ 17.63$ & 2 & 5 & 10 \\
\hline Asphalt overlay DGA $40 \mathrm{~mm}$ & AS40 & $\$ 23.58$ & 2 & 5 & 10 \\
\hline Asphalt overlay DGA $60 \mathrm{~mm}$ & AS60 & $\$ 35.33$ & 2 & 5 & 10 \\
\hline Asphalt overlays DGA $90 \mathrm{~mm}$ & AS90 & $\$ 48.35$ & 2 & 5 & 10 \\
\hline Asphalt overlays SMA $30 \mathrm{~mm}$ & SMA30 & $\$ 24.12$ & 2 & 5 & 10 \\
\hline Asphalt overlays SMA $40 \mathrm{~mm}$ & SMA40 & $\$ 29.56$ & 2 & 5 & 10 \\
\hline Asphalt overlay SMA $60 \mathrm{~mm}$ & SMA60 & $\$ 45.07$ & 2 & 5 & 10 \\
\hline Asphalt overlay SMA $90 \mathrm{~mm}$ & SMA90 & $\$ 59.85$ & 2 & 5 & 10 \\
\hline Asphalt overlay plus SAMI DGA $30 \mathrm{~mm}$ & SAS30 & $\$ 28.45$ & 2 & 7 & 12 \\
\hline Asphalt overlay plus SAMI DGA $40 \mathrm{~mm}$ & SAS40 & $\$ 34.40$ & 2 & 7 & 12 \\
\hline Asphalt overlay plus SAMI SMA $30 \mathrm{~mm}$ & SSMA30 & $\$ 34.94$ & 2 & 7 & 12 \\
\hline Asphalt overlay plus SAMI SMA $40 \mathrm{~mm}$ & SSMA40 & $\$ 40.38$ & 2 & 7 & 12 \\
\hline
\end{tabular}

Note: The costs would be expected to vary with size and/or location of job. The expected lives would also very depending on the traffic loading and environmental conditions (such as temperature, aging, healing and resting).

\section{E. Transverse Cracking}

Transverse cracking is cracks that are predominantly perpendicular to pavement centerline, and are not located over Portland cement concrete joints. Transverse cracks are generally caused by thermally induced shrinkage at low temperature. When the tensile stress due to shrinkage exceeds the tensile strength of the hot-mix asphalt pavement surface and then, crack occur [15], [16]. These cracks can be effectively treated with crack sealants. An unsealed crack with a mean width of less than $6 \mathrm{~mm}(0.25 \mathrm{in}$.); or a sealed crack with sealant material in good are described as low severity, and any crack with a mean width greater than $6 \mathrm{~mm}$ ( 0.25 in.) and less than $19 \mathrm{~mm}(0.75 \mathrm{in}$.) can be considered as medium severity, and this may also associated with low severity random cracking. Any crack with a mean width greater than or equal $19 \mathrm{~mm}$ can develop adjacent moderate to high severity random cracking [1], [21].

\section{PAVEMENT TEMPERATURE}

Characterization of the insitu strength performance of highways constructed using hot-mix asphalt (HMA) is difficult because of viscoelastic behavior [2], [22]. These component materials exhibiting various properties contribute to complex mechanical behaviour of HMA, which can be characterised as elastic viscos elastic, and plastic under different condition such as temperature, load application, and aging [3], [23], [24]. Diefenderfer, Al-Qadi and Diefenderfer [6] highlighted highways that are subjected to heavy loading can cause significant damage capacity of the pavement varies with temperature.

Asphalt is a viscoelastic material, which means that its stiffness is dependent on temperature and rate of loading. The fatigue damage, or cracking of an asphalt pavement caused traffic load is influenced by the stiffness properties of the mix and distribution of stresses and strain through this layer. The level of tensile strain in asphalt is dependent on temperature and this effect can be considered in terms of the influence of temperature on mix stiffness [25]-[27]. Deacon et al. [5] investigated the effect of temperature on pavement life and development of temperature equivalency factors for fatigue, performed controlled strain, flexural fatigue tests at four temperature ranging from $5^{\circ} \mathrm{C}$ to $25^{\circ} \mathrm{C}$ [26], [28]. The initial flexural stiffness and the slope of the initial strain-fatigue life were found to be sensitive to temperature.

\section{Pavement Management Systems (PMSs)}

Pavements are an important part of highway transportation infrastructure that constitutes an enormous investment of public funds. A tremendous amount of time and money is spent each year on construction of new pavements as well as on maintenance and rehabilitation (M\&R) of existing pavement. To maximize benefits and minimize overall costs, a systematic and scientific approach is needed to manage pavements [29]. Pavement management systems (PMSs) provide consistent, objective, and systematic procedures to determine priorities, schedule allocating resources and budgeting for pavement M\&R [30]. Typical unit costs and expected life typical pavement maintenance treatments are shown in Table III.

Pavement engineering management systems uses the systems approach to provide a unified treatment of pavement design, testing, construction, maintenance, evaluation, and restoration [31], [32]. Improving road safety through proper pavement engineering and maintenance should be one of the major objective of pavement management systems [33]. When pavement are evaluated in terms of safety, a number of factor related to pavement engineering properties are raised, such as pavement geometric design, pavement materials and mix design, pavement surface properties, shoulders type and pavement color and visibility [33]. A good pavement engineering management system requires an accurate and efficient pavement performance [34] so that prediction models based on the Pavement Condition Index and the age of the pavement can be developed. 


\section{RESULTS AND Discussions}

\section{A. Distress Identification and Characteristics}

A summary of most pavement distress and characteristic types of asphalt concrete surfaced pavements of Western Australia are shown in Table IV. From the data presented, it can be seen that the majority of asphalt surfaced pavements roads have fatigue, longitudinal and transverse cracking as compared to others types of distress. The crack mean widths of these are also high. This indicates the annual daily traffic (ADT) in heavily loaded urban roads has been increasing to cause all these pavement distress. The Strategic Highway Research Program [1] identified the pavement distress with asphalt concrete surfaced pavements into five main categories: cracking (fatigue, block, edge, longitudinal, reflection and transverse cracking); patching and potholes; surface deformation; surface defects and miscellaneous.

Guyer [35] evaluated pavement thickness that must be design to withstand the anticipated traffic roads for the design life of pavement. Increasing the grow weight by as little 10 percent can equivalent to increase the volume of traffic by as much as 300 to 400 percent and imposed largely a fatigue, longitudinal and transverse effect on the flexible pavement as a rapidly increased number of loads repetition per vehicle operation.

Distress with asphalt concrete surfaced pavements of high severity fatigue cracking is shown in Fig. 2. This longitudinal fatigue crack has a mean width of $20 \mathrm{~mm}$ and occurs in areas where subjected to repeated traffic loading (wheel paths). In the Distress Identification Manual for Long-Term Pavement Performance by Strategic Highway Research Program [1] described an area of moderately or severely spalled interconnected crack forming with a complete pattern as high severity cracking and cracks should immediately be sealed. Oregon Department of Transportation [15] on the Pavement Similarly, Distress Survey Manual has reported a single longitudinal fatigue should be considered to have a width of $12 \mathrm{~mm}(0.5 \mathrm{in}$.). If different severity levels exist with an area that cannot easily be distinguished and then, it should use highest severity level.

TABLE IV: Distress TyPes OF ASPHALt CONCRETE SURFACED PAVEMENT IN WESTERN Australia

\begin{tabular}{|l|l|l|l|l|}
\hline Road name & Mix type during construction & Cracking type & Defined severity levels & Crack widths (mm) \\
\hline Welshpool & AC14 -75 Blow & Transverse Cracking & Yes & 20.1 \\
\hline Mills & AC14 -75 Blow & Fatigue Cracking & Yes & 20.3 \\
\hline Kurnall & AC14 -75 Blow & Reflection Cracking & Yes & Yes \\
\hline Dowd & AC14 -75 Blow & Fatigue Cracking & Yes & 10.6 \\
\hline Carousel & AC10 -50 Blow & Longitudinal Cracking & Yes & 20.3 \\
\hline Carden & AC14 -50 Blow & Longitudinal Cracking & Yes & 18.6 \\
\hline Montrose & AC10 -35 Blow & Block Cracking & Yes & 10.6 \\
\hline Metcalf & AC10 -35 Blow & Potholes & Yes \\
\hline High & AC10 -75 Blow & Transverse Cracking & Yes & 240.4 \\
\hline Bannister & AC14 -75 Blow & Fatigue Cracking & Yes \\
\hline Vinicombe & AC14 -75 Blow & Longitudinal Cracking & Yes \\
\hline Riley & AC10 -50 Blow & No Cracking & 11.7 \\
\hline
\end{tabular}

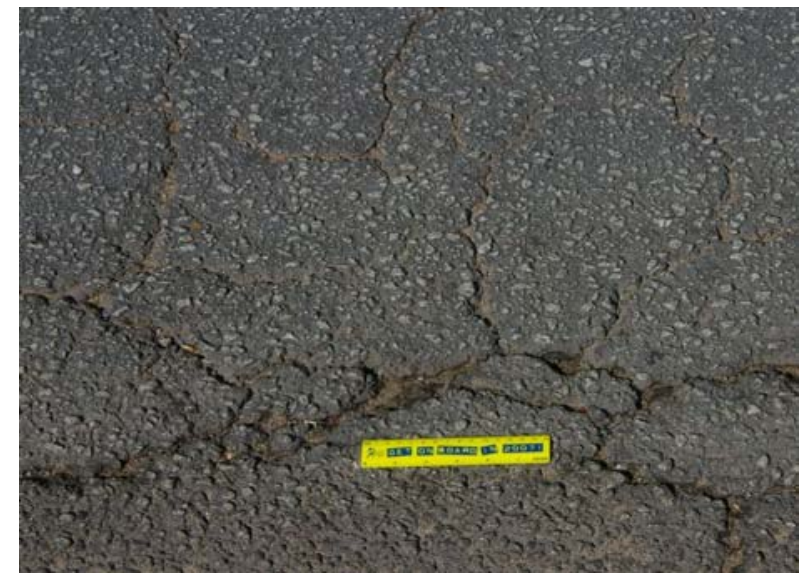

Fig. 2. High severity fatigue cracking.

A moderate block cracking of asphalt concrete surfaced pavement area is shown in Fig. 3. This crack has a mean width of $11 \mathrm{~mm}$. From the distress area, it can be seen that cracks divided the pavement surface into approximately rectangular pieces, and typically occurred throughout the pavement width, and not just in the wheel paths. Cracks with a mean width $>6 \mathrm{~mm}(0.25 \mathrm{in}$.) and $\leq 19 \mathrm{~mm}(0.75 \mathrm{in})$ can be considered as moderate severity block cracking [1].

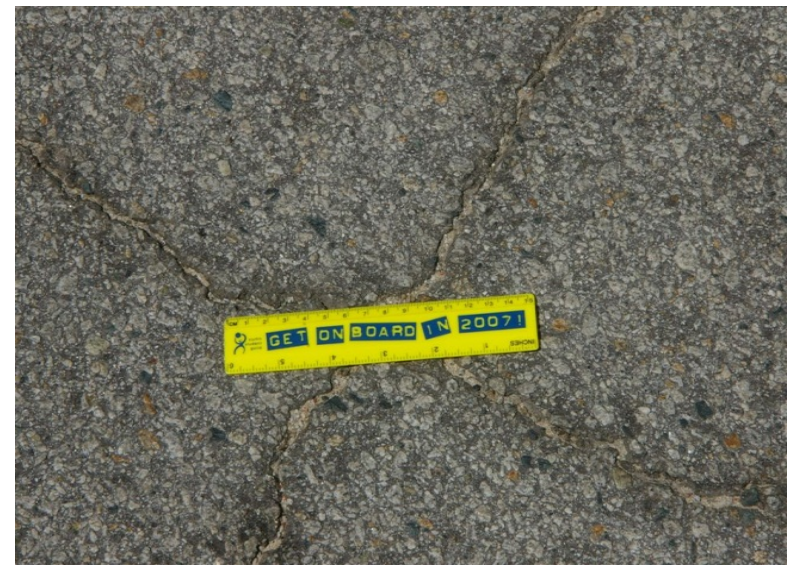

Fig. 3. Moderate severity block cracking.

A high severity longitudinal cracking of distress asphalt concrete surfaced pavements area is shown in Fig. 4. This crack has a mean width of $20 \mathrm{~mm}$. From the data presented, it can be seen that cracks are predominantly parallel to pavement centerline, which is located within the lane (wheel path versus non-wheel path) is significant. In the Distress Identification Manual for Long-Term Pavement Performance (LTPP) developed by Strategic Highway Research Program 
[1] and Pavement Distress Survey Manual developed by Oregon Department of Transportation [15] described any crack with a mean width $>19 \mathrm{~mm}$ (0.75 in.) is considered as high severity longitudinal cracking while any crack $\leq 19 \mathrm{~mm}$ as adjacent moderate to high severity random cracking.

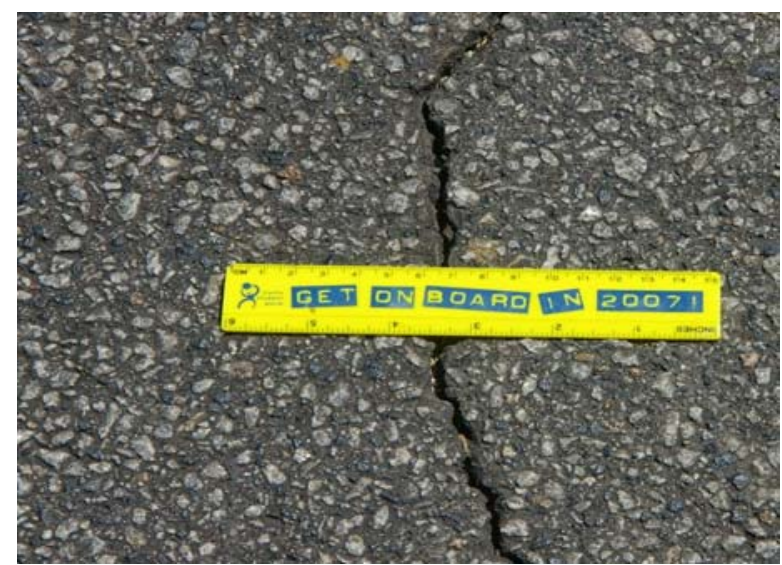

Fig. 4. High severity longitudinal cracking.

Asphalt concrete surfaced pavement with moderate severity reflection cracking is shown in Fig. 5. This crack has a mean width of $11 \mathrm{~mm}$. From the distress area, it can be viewed that cracks in the asphalt concrete are in the overlay surface, which was at joints. Any cracks with a mean width $>$ $6 \mathrm{~mm}(0.25 \mathrm{in})$ and $\leq 19 \mathrm{~mm}(0.75$ in. $)$ is considered as moderate severity reflection cracking [1], [18].

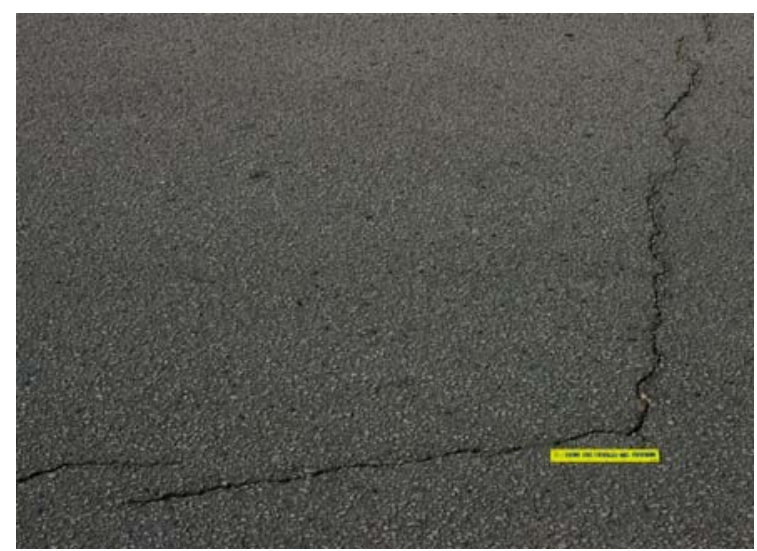

Fig. 5. Moderate severity reflection cracking.

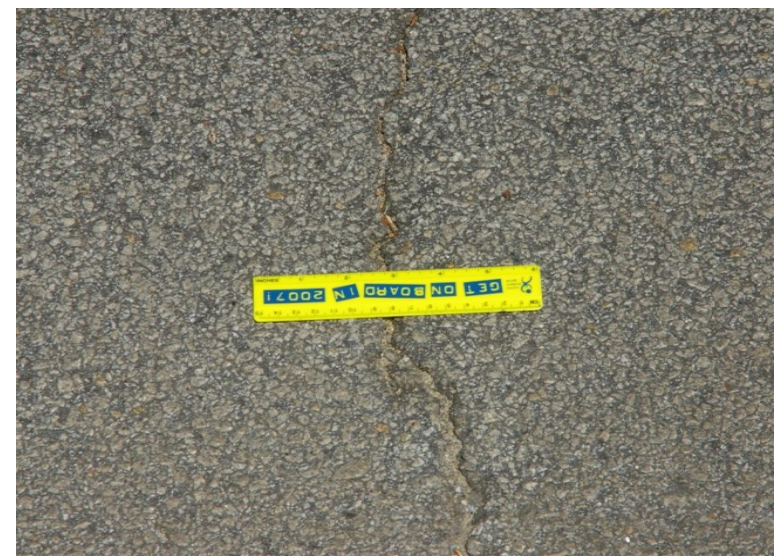

Fig. 6. Moderate severity transverse cracking.

Pavement distress with moderate severity transverse cracking is shown in Fig. 6. This crack has a mean width of $16 \mathrm{~mm}$. From the data presented, it can be viewed that cracks are predominantly perpendicular to pavement centerline, and are not actually located over Portland cement joints. According to [1], [15], [18], any crack with a mean width $>6$ $\mathrm{mm}(0.25 \mathrm{in})$ and $\leq 19 \mathrm{~mm}$ (0.75 in.) is considered as moderate severity transverse cracking. Fig. 7 shown asphalt concrete surfaced pavement with no cracking.

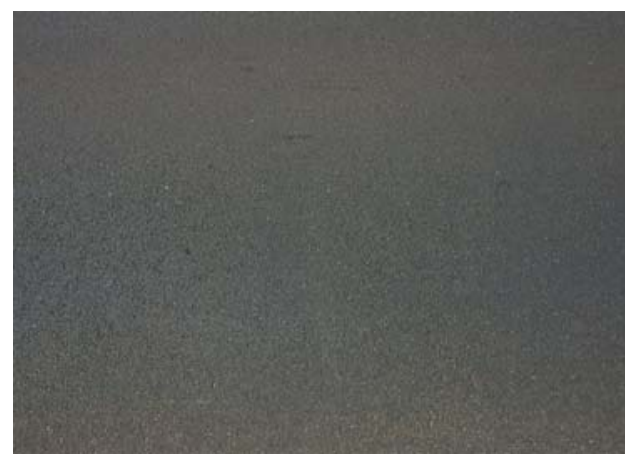

Fig. 7. Pavement with no cracking.

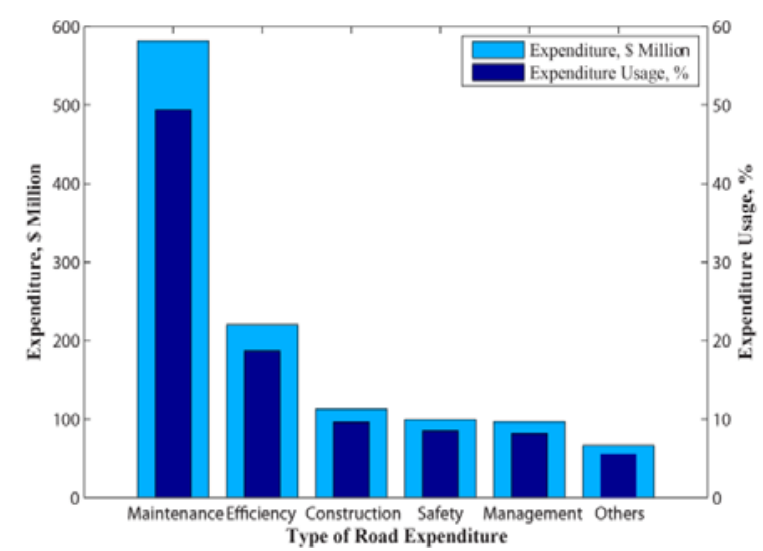

Fig. 8. Road expenditure cost analysis for main roads western australia.

\section{B. Cost Analysis}

A summary of cost analysis for road expenditure of Main Roads Western Australia is shown in Fig. 8. From the data presented, it can be seen that road maintenance had high cost of Aus $\$ 581.475$ million as compared to the others expenditure. Results are shown that a tremendous amount of time and many spent each year on maintenance and rehabilitation of existing pavement as well as on construction new pavements. Lee, Park and Mission [29] recommended a systematic and scientific approach to maximum benefits and minimize overall costs so that long-term pavement performance will be managed and achieved. The non-linear model for pavement maintenance and rehabilitation optimization (1) to (6) was used to predict, evaluate and analysis the cost expenditure of pavement distress condition based on real expenditure of road maintenance and rehabilitation of WA.

Cost analysis predicting non-linear model using probabilistic network chain process for different type of cracking of asphalt concrete surfaced pavement are shown Fig. 9. From the data demonstrated, it can be seen that all cost analysis predicting have a similar patterns apart Caption (a) is shown for a year 2011 while Caption (b) and (c) for 2012 and 2013 , repectively. From the predict model analysis, it can be seen that the cost for fatigue and longitudinal cracking are high and similar in pattern as compared to block, reflection and transverse cracking. This indicates that a tremendous 
amount of time and money has been spending to fatigue and longitudinal cracking maintenance and rehabilitation. Deterioration of flexible pavement can be increased because of traffic loading and environmental factors in a heavily urban roads According the FHWA guide fatigue cracking should not exceeding 25 percent of the total area within the first 15 years' service [36]. Pavement management systems (PMSs) provide consistent, objective, and systematic procedures to determine priorities, schedule allocating resources and budgeting for pavement M\&R [30], [32].

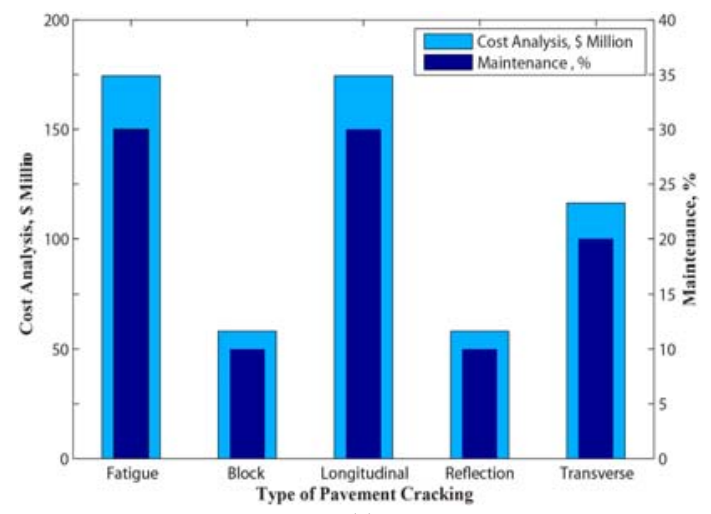

(a)

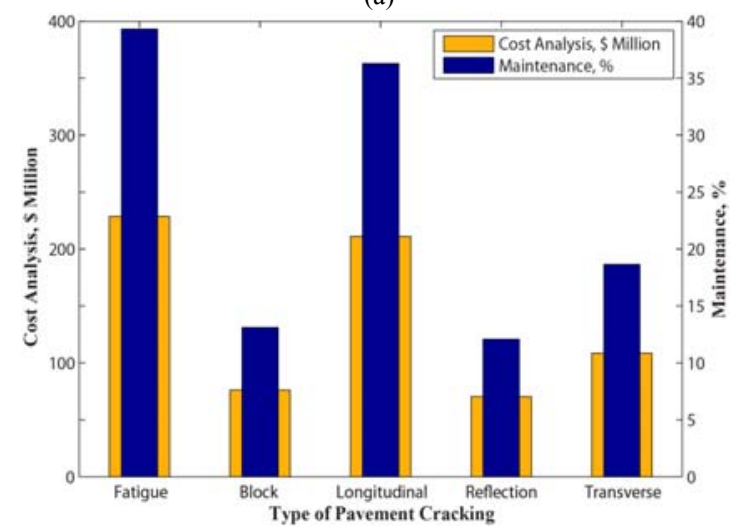

(b)

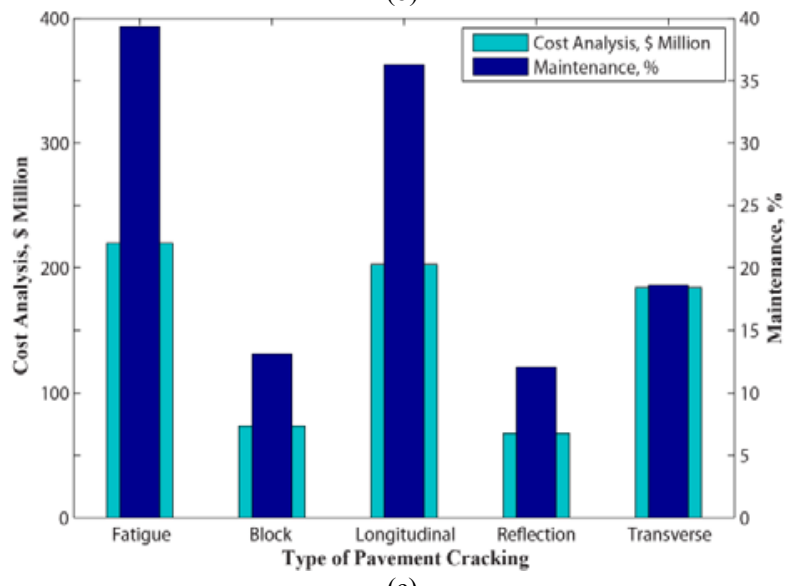

(c)

Fig. 9. Caption (a), (b) and (c) cost analysis for different type of pavement cracking of asphalt concrete surfaced pavement in year; 2011, 2012 and 2013 of western australia.

\section{Calibration and Validation of SDSM Model}

The future pavement temperature predicted using the SDSM model in downscaling GCM temperature for the selected regions are shown in Fig. 10. From the data performed, it can be seen that all future temperature predicted for all selected regions have almost a similar results and followed similar patterns. Thus to avoid a repetition, results has presented only for Perth heavily urban roads regions. Caption (a) is shown average daily maximum temperature, whereas Caption (b) is average daily minimum temperature. From the predicted analysis, it can be seen that future maximum and minimum daily temperature forecast for Perth region shows increasing trend for the period of 2011-2040 while it shows a decrease for the period of 2071-2100.

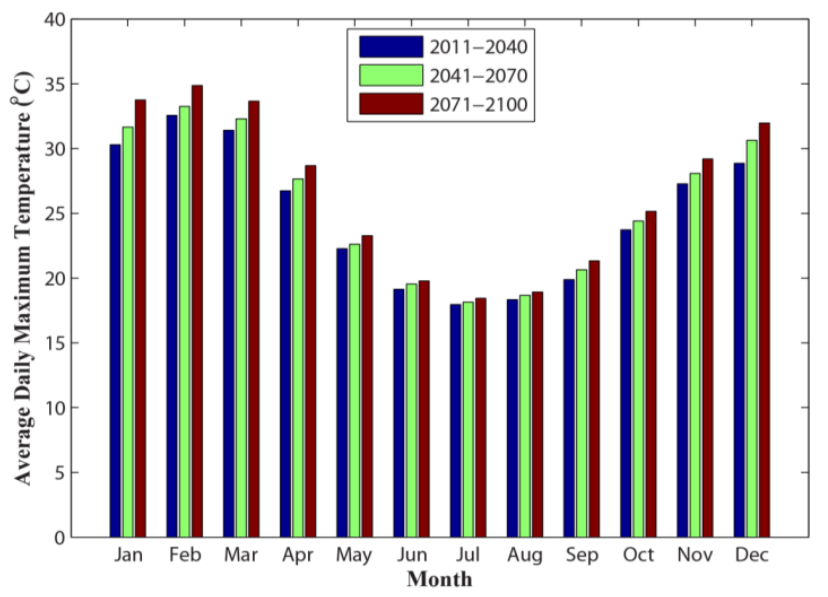

(a)

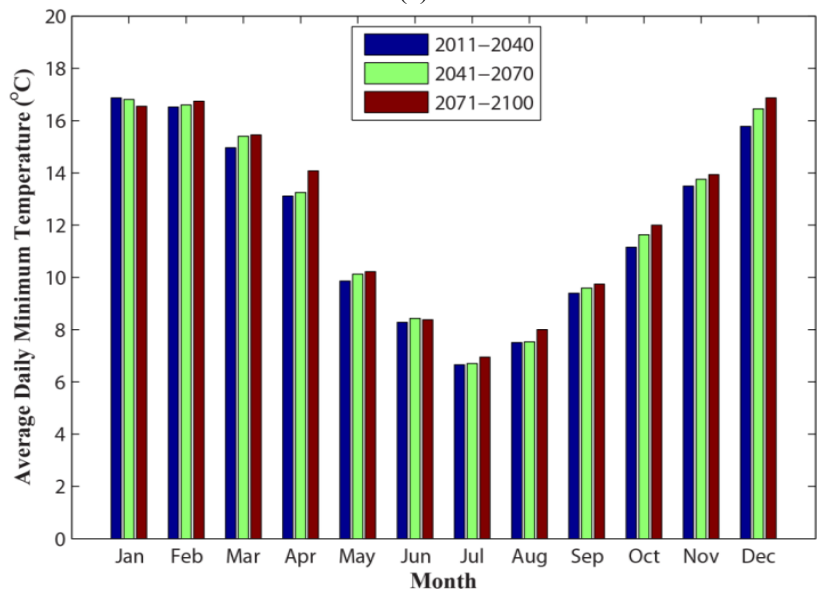

(b)

Fig. 10. Prediction of future daily average maximum and minimum pavement temperature.

The predicted model shows a significant increment of daily maximum and minimum daily temperature for summer months (December to March). For example, January has an average daily maximum temperature of $30{ }^{\circ} \mathrm{C}$ for the period 2011-2040 while $32{ }^{\circ} \mathrm{C}$ and $34{ }^{\circ} \mathrm{C}$ for $2040-2070$ and 2071-2100, repectively. Therefore, this temperature increment should be taken into account for the sensitive flexible pavement design process so that long-term pavement performance can be achieved. However, average daily minimum temperature in January does not show increasing tread but decreasing in tread. This showed that minimum temperature increment takes low value as compared to maximum temperature increment, and this temperature variation in a large range with a short period of time can affect the flexible pavement design and pavement performance.

Mills, Tighe, Andrey, Huen, and Pam [37] described that temperature variation in a huge range can highly affect the performance of pavement infrastructure, and create different type of pavement distress. Similarly, Mills, Tighe, Andrey, Smith, and Huen [7] analyzed the effect of temperature 
variation for flexible pavement design, and recommended that pavement engineers should take into consideration to the temperature variations during pavement design. Maintenance and rehabilitation (M\&R) to the pavement distress should require earlier in the design life.

\section{CONCLUSIONS}

Distress identification, prediction of cost analysis for pavement distress and pavement temperature for long-term pavement performance has been achieved. The Markov Chain process (non-linear model) approach and the statistical downscale (SDSM) model can be used to evaluate and analysis the pavement temperature for long-term pavement performance. It is highly recommended to use a systematic and scientific approach to maximum benefits and minimize overall costs so that long-term pavement performance will be achieved.

\section{ACKNOWLEDGMENT}

Authors would like acknowledge the financial support for this study, which was provided by Australia Postgraduate Awards (APA) and Curtin Research Scholarship (CRS). Mr. Colin Leek, Engineer for Canning Vale, for assisting during the field survey. Main Roads Western Australia and Austroads, Bureau of Metrology of Western Australia for providing data for modeling pavement temperature are appreciated.

The options, findings and conclusions expressed in this publication are not necessary those of Australia Postgraduate Awards, Curtin Research Scholarship or Mainroads Western Australia.

\section{REFERENCES}

[1] Strategic Highway Research Program, "Distress identification manual for the long-term pavement performance project," Strategic Highway Research Program-National Research Council, Washington, DC. FHWA Publication Report No. SHRP-P-338, May 1993.

[2] A. Nega, H. Nikraz, and C. Leek, "Engineering Characterization of Hot-Mix Asphalt in Western Australia," Airfield and Highway Pavement: Sustainable and Efficient Pavement, I. Al-Qadi and S. Murrell, Eds., ed Los Angeles, California, USA: American Society of Civil Engineers, 2013, pp. 987-998.

[3] A. Nega, H. Nikraz, C. Leek, and B. Ghadimi, "Pavement materials characterization of hot-mix asphalt mixes in Western Australia," Advanced Materials Research, vol. 723, pp. 434-443, 2013.

[4] A. Bayat, H. A. Kasani, and H. R. Soleymani, "Investigation of temperature dependency of asphalt concrete using laboratory dynamic modulus and field deflection testing," Transporation Research Board, Washington, DC. TRB 2011 Annual Meeting, January 2011.

[5] J. A. Deacon, J. S. Coplantz, A. A. Tayebali, and C. L. Monismith, "Temperature considerations in asphalt-aggregate mixture analysis and design," Transportation Reseach Record No. 1454, Asphalt Concrete Mixture Design Performance, ed Washington, DC, USA: Transportation Reseach Board, 1994, pp. 97-112.

[6] B. Diefenderfer, I. Al-Qadi, and S. Diefenderfer, "Model to Predict Pavement Temperature Profile: Development and Validation," Journal of Transportation Engineering, vol. 132, pp. 162-167, 2006.

[7] B. Mills, S. Tighe, J. Andrey, J. Smith, and K. Huen, "Climate change implications for flexible pavement design and performance in Southern Canada," Journal of Transportation Engineering, vol. 135, pp. 773-782, 2009

[8] Main Roads Western Australia, "Annual Report," Main Road Western Australia, Perth, WA, Australia,July 2007.

[9] L. Gao, E. Y. Chou, and S. Wang, "Comparison of pavement network management tools based on linear and non-linear optimization methods," pp. 1-18, 2010.
[10] F. S. Hillier and G. J. Lieberman, Introduction to operations research, 9th ed. Belmont, California: McGraw-Hill, 2010.

[11] K. A. Abaza and S. Ashur, "Optimum decision policy for management of pavement maintenance and rehabilitation," in Transportation Research Record: Journal of the Transportation Research Board, No. 1655, ed Washington, DC: Transportation Research Board of the National Academies, 1999, pp. 8-15.

[12] A. A. Butt, M. Y. Shahin, S. H. Carpenter, and J. V. Carnahan, "Application of Markov process to pavement management system at network level," in Proc. 3rd International Conference on Managing Pavements, Washington, DC, 1994, pp. 159-172.

[13] X. Chen, S. Hudson, M. Pajoh, and W. Dickinson, "Development of new network optimization model for Oklahoma Department of Transportation," Transportation Research Record: Journal of the Transportation Research Board, No. 1524, Washington, DC, 1996, pp. 103-108.

[14] R. L. Wilby, C. W. Dawson, and E. M. Barrow, "Sdsm - a decision support tool for the assessment of regional climate change impacts," Environmental Modelling \& Software, vol. 17, pp. 145-157, 2002.

[15] Oregon Department of Transportation, "Pavement distress survey manual," Pavement Services Unit, Oregon Department of Transportation, Oregon, USA, June 2010.

[16] F. L. Roberts, P. S. Kandal, E. R. Brown, D. Lee, and T. W. Kennedy, Hot Mix Asphalt Materials, Mixture Design and Contruction, 2nd ed. Lanham, Maryland, USA: NAPA Research and Education Foundation, 1996.

[17] F. L. Roberts, L. N. Mohammad, and L. B. Wang, "History of hot mix asphalt design in the United States," Journal of Materials in Civil Engineering, vol. 14, pp. 279-293, 2002.

[18] K. L. Smith and A. R. Romine, "Materials and procedures for sealing and filling cracks in asphalt-surface pavements: Manual of practice," Federal Highway Administration, Washington, DC Report No. FHWA-RD-99-147, June 1999.

[19] R. E. Smith, "Overview of pavement management systems," in Proc. 29th Annual Convention International Slurry Surfacing Association, New Orleans, Louisiana, 1991, pp. 47-55.

[20] R. E. Smith, M. I. Darter, M. Y. Shahin, and T. R. Zimmer, "Pavement maintenance management study in the San Francisco Bay Area," vol. I, II, and Ill," Eres Consultants, Inc., Champaign, Illinois, 1984 .

[21] Strategic Highway Research Program, "Standard method of test for determining the fatigue life of compacted bituminous mixtures subjects to repeated flexural bending M-009," The Superpave Mix Design System Manual of Specifications, Test Methods and Practice, 1994, pp. $1-253$.

[22] I. L. A. Qadi, P. Yoo, M. Elseifi, and S. Nelson, "Creep Behavior of Hot-Mix Asphalt due to Heavy Vehicular Tire Loading," Journal of Engineering Mechanics, vol. 135, pp. 1265-1273, 2009.

[23] Y. B. Dibike, S. Velickov, D. Solomatine, and M. B. Abbott, "Model induction with support vector machines: introduction and applications," Journal of Computing in Civil Engineering, vol. 15, pp. 208-216, 2001.

[24] K. Gopalakrishnan and S. Kim, "Support vector machines approach to HMA stiffness prediction," Journal of Engineering Mechanics, vol. 137, pp. 138-146, 2011.

[25] R. C. Koole, C. P. Valkering, and F. D. R. Stapel, "Development of pavement design program for use on personal computer," in Proc. the 5the Conference on Asphalt Pavements for Southern Africa (CAPSA 5), Manzini, Swaziland, 1989, pp. 33-43.

[26] S. C. S. Rao Tangella, J. Craus, J. A. Deacon, and C. L. Monismith, "Summary report on fatigue response of asphalt mixtures, Prepared for Strategic Highway Research Program Project A-003-A," Institute of Transportation Studies, University of California, Berkeley, California, Prepared for Strategic Highway Research Program Project A-003-A TM-UCB-A-003A-89-3, February 1990.

[27] L. F. Walubita, "Comparison of faigure analysis approaches for prediction fatige lives of hot-mix asphalt concrete (HMAC) mixtures," PhD Thesis, Department of Civil Engineering, Texas A\&M University, USA, Texas, USA., 2006.

[28] P. Baburamani, "Asphalt fatigue life predication models - a literature review," ARRB Transport Research Ltd, Vermont South, Victoria, Australia, 1999.

[29] S. T. Lee, D. W. Park, and J. L. Mission, "Estimation of pavement rehabilitation cost using pavement management data," Structure and Infrastructure Engineering, vol. 9, pp. 458-464, 2013.

[30] Federal Aviation Administration, "Airport pavement management program," Federal Aviation Administration (FAA), Washington, DC Advisory Circular AC 150/5380-7A, October 2006.

[31] R. C. G. Haas and W. R. Hudson, Pavement Management System. New York, U.S.A: McGraw-Hill, 1978. 
[32] A. Nega, H. Nikraz, and C. Leek, "Comparison of pavement network management tools and its probabilistic of pavement engineering for Western Australia," in Proc. Seventh International Conference on Construction in the 21st Century: Challenges in Innovation, Integration and Collaboration in Construction and Engineering, Bangkok, Thailand, 2013, pp. 1-13.

[33] S. L. Tighe, N. Li, L. C. Falls, and R. Haas, "Incorporating road safety into pavement management," Transportation Research Record: Journal of the Transportation Research Board, vol. 1699, pp. 1-10, 2000.

[34] A. A. Butt, M. Y. Shahin, K. G. Feighan, and S. H. Carpenter, "Pavement performance predication model using the Markov Process," Transportation Research Record: Journal of the Transportation Research Board, vol. 1123, pp. 12-19, 1987.

[35] J. P. Guyer, An introduction to flexible pavement design, ed. Stony Point, NY: Continuing Education and Development, Inc., 2009, pp. $1-28$.

[36] R. Stubstad, R. Carvalho, R. Briggs, and O. Selezneva, "Simplified techniques for evaluation and interpretation of pavement deflections for network-level analysis: Guide for assessment of pavement structural performance for PMS applications," Federal Highway Administration, U.S. Department of Transportation, McLean, VA FHWA-HRT-12-025, June 2012.

[37] B. Mills, S. Tighe, J. Andrey, K. Huen, and S. Parm, "Climate change and the performance of pavement infrastructure in southern Canada: Context and case study," in Proz. Engineering Institute of Canada (EIC) Climate Change Technology Conference, 10-12 May, Ottawa, Canada, 2006, pp. 1-9.

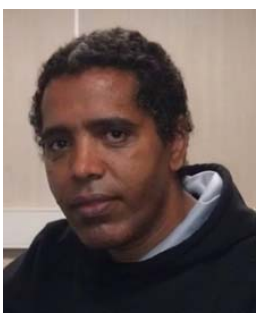

Ainalem Nega is currently a $\mathrm{PhD}$ Candidate at Department of Civil Engineering, Curtin University in Perth, Australia. He is under supervision of Professor Hamid Nikraz and Professor Imad L. Al-Qadi. He has a MEngSc. -research degree in hydrology (2011) from the University of Western Australia. He also holds a BEng. in mining and environmental Engineering degree from the Western Australia School of Mines, Curtin University of Technology (2007).

$\mathrm{He}$ is currently working as a lecturer at Curtin University in Perth, Australia while he is also studies his $\mathrm{PhD}$ in civil engineering. He was a lecturer at Western Australia School of Mines (WASM) in 2011 and was involved in casual academic teaching and Tutoring at the University of Western Australia since 2008 till his MEngSc.-research degree finished in 2011. He had also worked with SGS Lakefield Oretest Pty.Ltd, Operating Uranium Pilot Plant and Kimberley Diamond Company (Vacation Student Employment) in Australia in 2011 and 2006, respectively and other NGO's such as UNHER, LWF and Norwegian Save the Children as Supervisor in Kenya. He has published 11 papers in refereed journals articles and international conferences proceedings in the area of pavement materials engineering and pavement numerical modelling.

His research interests are focused on civil engineering and pavement materials, highway and airfield pavement mechanics, advance modeling including viscoelastic respond to the traffic loading, pavement design, pavement fracture, assess pavement performance, engineering pavement management systems, pavement condition assessment and modeling of pavement interface and layer. 